\title{
Effects of temporal uncertainty on watchkeeping performance'
}

RICHARD P, SMITH, JOEL S. WARM AND EARL A. ALLUISI

UNIVERSITY OF LOUISVILLE

Two experiments were conducted to assess the relative effects of signal density and regularity on watchkeeping performance. In Experiment I, three levels of density $(6,24$, and 95 signals hr.) were combined factorially with three levels of variability (coefficients of variation of $0.01,0.10$, and 1.00), and $10 \mathrm{Ss}$ were assigned at random to each of the nine conditions. In Experiment II, five levels of density (6, $12,24,48$, and 96 signals/hr.) were combined with the same three levels of variability, and $13 \mathrm{Ss}$ were assigned to each condition. Each $S$ monitored a visual "blinking-lights" display for an hour under instructions to detect and report the occurrence of certain "critical signals," i.e., arrests of alternation of the lights. Response times (RT's) to correctly detected signals in both experiments decreased as a linear function of logarithmic increases in signal density. An uncertainty metric, the signal surprisal due to density, was derived, and the watchkeeper's RT was expressed as an increasing linear function of this measure of temporal uncertainty. Interpretation of these and other data support a functional, psychophysical approach to the study of watchkeeping behavior.

The uncertainty of the critical signal in a watchkeeping task can be expected to affect performance (cf., Alluisi, 1966, pp. 206-208). Indeed, the kind and degree of uncertainty define, at least in part, the difficulty of the watchkeeping task.

In one of the earliest of watchkeeping studies, Mackworth (1950, pp. 53-63) reported that the deterioration in correct signal detections which typically occurred in his synthetic radar task could be delayed by increasing the brightness of the critical signals. This suggests that watchkeeping performance is a decreasing function of stimulus uncertainty (uncertainty concerning the nature of the critical signal). That is to say, as the signal-tonoise ratio of the critical signal is increased, performance efficiency also can be expected to increase. Although there have been few, if any, functional studies of stimulus uncertainty, it has been well established that this kind of uncertainty is likely to have some effect on watchkeeping performance (e.g., Adams, 1956; Bartlett et al, 1955; Jenkins, 1953, 1958).

Spatial uncertainty (uncertainty concerning where the signal will appear) has been found to affect performance in visual watchkeeping tasks. Mackworth (1950, pp. 5859), again using his synthetic radar task, found a progressive decline in the incidence of missed signals with rising spatial expectancy, or decreasing spatial uncertainty, and essentially similar results have been reported by other investigators (Deese \& Ormond, 1953; Bartlett et al, 1955; Nicely \& Miller, 1957; Adams \& Boulter, 1964).

The third major source of uncertainty has also been studied; this is temporal uncertainty, or uncertainty concerning when a critical signal will occur. Both Ditchburn (1943) and Mackworth (1950) report that changes in the temporal intervals between signals produced associated changes in the proportions of signals missed. It appears from the results of later studies that changes either in signal frequency or in signal regularity may affect performance efficiency in watchkeeping tasks (e.g., Baker, 1959a, b; 1963; Bartlett et al, 1955; Broadbent, 1958; Deese, 1955; Deese \& Ormond, 1953; Jenkins, 1958; Smith, 1961).

These findings suggest that a psychophysical approach could be taken in studying watchkeeping performance, provided, of course, that the physical aspects of the uncertainty of the critical signal can be quantified and controlled. Such an approach has been taken in the present study in an attempt to determine the psychophysical relations between watchkeeping performance on the one hand, and the temporal uncertainty of the critical signal on the other.

\section{METHOD}

Two experiments were conducted with essentially the same procedure, but with minor differences in apparatus and in the population of Ss sampled, and with two relatively important differences in design: (a) Three levels of signal variability were combined factorially with three levels of signal density in Experiment I, but with five levels of signal density in Experiment II, and (b) the duration of the critical signal was different in the two experiments. In Experiment I, the critical signal was continued until $S$ responded to it, thereby precluding S's missing (or failing to respond to) a signal; in Experiment II, on the other hand, if $S$ failed to respond to the critical signal within approximately 20 sec., the signal was removed and he was scored as having missed the signal. The two experiments will be described separately in this section.

\section{Experiment I}

Signal metrics. When man is confronted with a task in which he overtly or covertly attempts to predict when an event will occur, at least two sources of variability (unpredictability or uncertainty) may be identified. The 
first is the objective variability of the intersignal interval (ISI) distribution, and the second is a subjective factor; namely, S's ability to make precise estimates of temporal duration, at least, to the extent that temporal discrimination is dependent on the durations to be judged (cf., Warm et al, 1963; Woodrow, 1951). This subjective factor may be related to the mean of the ISI distribution (or average duration to be estimated or predicted). Similarly the objective factor may be related to the relative variance of the ISI distribution, or to the coefficient of variation-the ratio of the standard deviation to the mean of the ISI distribution. Differences in the means of the ISI distributions used will be referred to as differences in signal density; differences in the coefficients of variation will be called differences in signal regularity.

Three levels of signal density $(6,24,96$ signals $/$ hr., or ISI means of $600,150,37.5 \mathrm{sec}$, respectively) were combined factorially with three levels of signal regularity (coefficients of variation of $0.01,0.10$, and $1.00)$ to produce nine experimental conditions. The statistical ISI distributions were identical in shape for all nine conditions. They approximated the right-hand half of a normal distribution (for additional details, see Smith, 1961).

Apparatus. The display confronting $\mathrm{S}$ consisted of two, $6-v$ pilot lights that were set 1 in. apart and located one above the other on a black wooden surface. The lights flashed alternately at a rate of 2 flashes/sec. Occasionally, the alternation ceased and just one of the lights (either top or bottom) continued to flash. The overall rate of flash remained the same (2/sec.) whether both or only one of the lights flashed. The arrest of alternation of the flashing lights was the critical signal to which $\mathrm{S}$ responded.

A key was fixed to the arm rest of S's chair, and he was instructed to press the key as quickly as possible whenever he detected a signal, but to avoid false responses. Once presented, a signal was continued until $S$ responded, whereupon the signal was removed and the lights reverted to alternate flashing.

Both $S$ and the display were located in a $5-$ by $8-\mathrm{ft}$. experimental booth from which extraneous light and sound were excluded. A low level of general illumination was provided by a $15-\mathrm{w}$ bulb; the bulb was placed in a parabolic reflector aimed at the ceiling of the booth behind $\mathrm{S}$. Masking noise was provided by an overhead ventilation fan mounted in the wall of the booth, and by approximately $75 \mathrm{~dB}$ of broad-band noise gelivered through earphones that $\mathrm{S}$ wore.

Except for S's display and response key, all equipment was located at E's station outside of, but adjacent to the experimental booth. The flashing of the display lights was controlled by three micro switches driven by an adaptable-speed continuous timer (Gorrell and Gorrell) and suitable relay circuitry, and the times of occurrence of the critical signal (the arrest of alterna- tion) were controlled with use of two Hunter Interval Timers (model III-C). The order of presentation of ISIs from a given distribution was random and different for each S. Reaction time (RT), i.e., the time between the presentation of the critical signal and S's response to it, was measured to the nearest 0.01 sec. by using a Standard Electric Timer (model $S-1$ ).

Subjects. Ninety undergraduate students at Emory University ( 45 men and 45 women) volunteered to serve as Ss; none had previously served in any watchkeeping study. Ten Ss were assigned at random to each of the nine experimental conditions with the restriction that an equal number of males and females was assigned to each cell.

Procedure. Only one $\mathrm{S}$ was permitted in the experimental booth at any one time. He was seated, facing the display, and instructed with regard to the "normal" alternation of the flashing lights and the "critical signal" or arrest of alternation. A brief training period followed during which $S$ was shown and was required to respond correctly to two critical signals. This provided $\mathrm{E}$ some assurance that the instructions had been understood and that $S$ could detect and respond to signals appropriately. Following the training period, $S$ remained alone in the experimental booth, and the 1-hr. watch began. No clock or watch was permitted in the experimental booth, so $\mathrm{S}$ had no external aid to assist him in judging the passage of time. No knowledge-ofresults information was provided by $\mathbf{E}$, but the task itself provided a certain kind of knowledge-of-results information in that the arrest of alternation (critical signal) would continue until S responded to it, whereupon the alternation would begin anew.

\section{Experiment II}

Signal metrics. Five levels of signal density $(6,12$, $24,48,96$ signals/hr., or ISI means of $600,300,150$, $75,37.5 \mathrm{sec} .$, respectively) were combined factorially with three levels of signal regularity (coefficients of variation of $0.01,0.10$, and 1.00 ) to produce 15 experimental conditions. The statistical ISI distributions approximated the right-hand half of a normal distribution in each of the 15 cells. The distributions used in the nine cells that replicated Experiment I were identical to those used in that study.

Apparatus. The apparatus was essentially identical to that of Experiment I, except that the timing of the critical signals was accomplished with a Gerbrands punched-tape timer (in place of the Hunter Interval Timers), and the flashing of the lights was controlled by an Industrial Timer Corp. continuous-duty rotary cam timer (in place of the Gorrell and Gorrell timer). In addition, the apparatus was modified to permit the use of up to five displays and response keys simultaneously, and the RTs were measured to the nearest 0.1 sec. with use of Sodeco impulse counters (model TCe) pulsed 10 times per sec. (in place of the Standard 
Electric Timers).

The two display lights were mounted on a wooden panel, approximately 6 in. square. About 1 in. below the lower of the two lights, a push-button response switch was mounted, and the entire panel was mounted in an experimental booth above a work-surface table, approximately $28 \mathrm{in}$. in front of, and at the eye level of the seated S. The critical signal, when it appeared, was continued until $S$ responded to it, whereupon the normal alternation of the flashing lights was re-established; in the event $\mathrm{S}$ failed to respond within $19.8 \mathrm{sec}$. from the arrest of alternation, the signal was removed, the alternation re-established, and $S$ was scored as having missed the signal.

The experimental room contained five booths. Each booth was approximately 5 by $4 \mathrm{ft}$. in floor surface, open at the rear, but with walls extending sufficiently far back to prevent one $S$ from observing the activities of any other S. Ambient illumination was provided by a single 75-w red bulb mounted in a ceiling fixture and covered with a diffusing shade. Approximately $78 \mathrm{~dB}$ of broad-band noise were provided through use of an inclosed wide-range 12-in. speaker mounted in the experimental room; this noise served to mask extraneous sounds, including the sounds of the control equipment that was located in an adjacent room.

Subjects. A total of 195 undergraduate students at the University of Louisville (108 men and 87 women) volunteered to serve as $\mathrm{Ss}$ in this experiment; none had previously served in any watchkeeping study. Each of the 15 experimental conditions was assigned 13 Ss at random. An attempt to assign exactly seven males and six females to each experimental group was not successful (there being three fewer women than necessary to accomplish this), but no cell contained more than eight males nor fewer than five females.

Procedure. From two to five Ss were run simultaneously (see Morgan \& Alluisi, 1965, for evidence of independence of performances obtained from individual watchkeepers under such conditions). All Ss were seated at their stations, each facing his display, and instructed with regard to the "normal" alternation of the flashing lights and the "critical signal" or arrest of alternation. Each $S$ was instructed to respond to the signal by pressing the push-button on his display as quickly as possible after his having detected the presence of a signal, but to avoid false responses insofar as possible. Communication between Ss was not permitted during the course of the watch, and $E$ 's monitoring with use of a listening device revealed no instances of communication between or among Ss.

A 5-min. training period was presented; during this period a total of three critical signals occurred, and $S$ was required to respond to each of these. During the training period, E remained in the experimental room in order to be able to observe $\mathrm{Ss}$, to answer any questions that arose, to correct any misconceptions concerning the nature of the task that became apparent, and to assure himself that Ss understood the task. Following the training period, E returned to the adjacent room with the control equipment and the $1-\mathrm{hr}$. watch was begun.

As in Experiment I, no clock or watch was permitted in the experimental room, and $\mathrm{S}$ had no external aids to indicate the passage of time. No knowledge-of-results information was provided beyond that which is intrinsic to the task itself.

\section{RESULTS}

Response time. Each S's median response time (RT) to his correct signal detections was computed, and then the mean of these RTs was computed for each of the nine experimental conditions of Experiment I and the 15 conditions of Experiment II; these data are shown in Figs. 1 and 2 for each of the two experiments respectively.

An analysis of variance of the data of Experiment I (Fig. 1) indicated significant effects between cells $(F=11.87, d f=8 / 81, p<.01)$. When the variance was partitioned according to the factorial design, the densityby-regularity interaction was statistically significant $(F=6.99, \mathrm{df}=4 / 81, p<.01)$. In order to understand more clearly the nature of this interaction, an alternative partitioning by orthogonal components was computed. In addition, trend analyses were computed, using the logarithmically equal spacings of the densities overall, and of the regularities at each level of signal density.

The results of these analyses indicated that the differences due to signal density were statistically significant $(F=30.07, d f=2 / 81, p<.01)$ as was also the (log) linear regression $(F=60.10$, $d f=1 / 81, p<.01)$, but not the deviations from regression ( $F<1.00$ ). The effects of signal regularity within the density level of

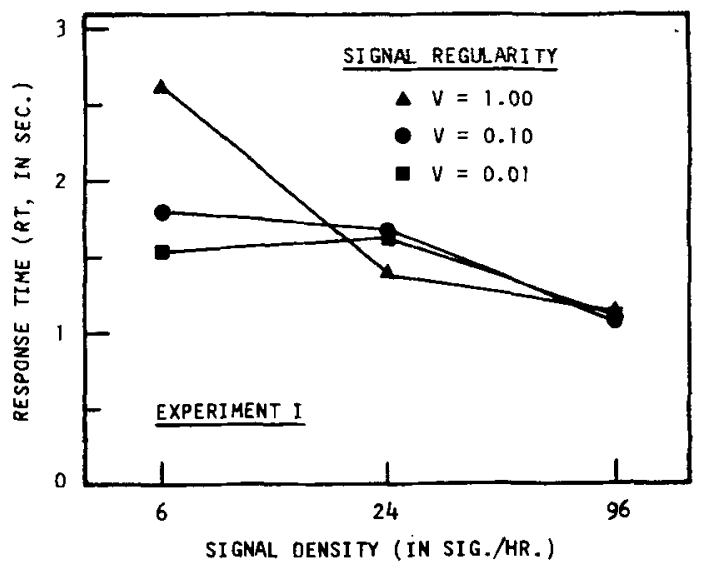

Fig. 1. Response time to correct signal detections as a function of signal density at three levels of signal regularity (coefficients of variation of 1.00, 0.10, and 0.01). Data of Experiment I. Note that the abscissa is plotted on a logarithmic scale. 


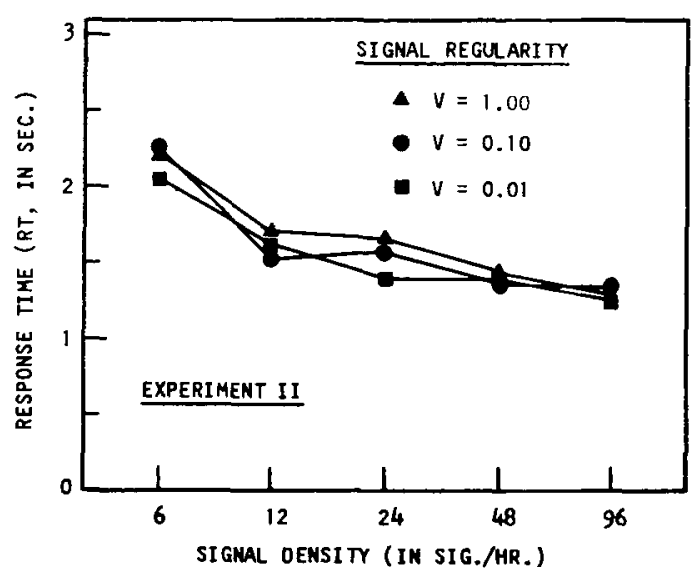

Fig. 2. Response time to correct signal detections as a function of signal density at three levels of signal regularity. Data of Experiment II. Note that the abscissa is plotted on a logarithmic scale.

6 signals $/ \mathrm{hr}$. were statistically significant $(\mathrm{F}=16.14$, $\mathrm{df}=2 / 81, p<.01)$, as was also the $(\log )$ linear regression $(\mathrm{F}=29.59, \mathrm{df}=1 / 81, \mathrm{p}<.01)$ with no significant deviations from regression $(F=2.68, d f=1 / 81, p>.05)$. Signal regularity had no significant effect at either the 24-signals/hr. density level $(F=1.18$, $\mathrm{df}=2 / 81$, $\mathrm{p}>.05)$ or the 96-signals/hr. density level $(\mathrm{F}<1.00)$.

Analyses of the data of Experiment II (Fig. 2) yielded essentially identical results, except that none of the signal-regularity effects was statistically significant. Statistically significant effects were obtained between cells $(F=2.75, \mathrm{df}=14 / 180, \mathrm{p}<.01)$ and between levels of signal density $(F=9.09$, df $=4 / 180, p<.01)$. The (log) linear regression of signal density was significant $(F=30.62, d f=1 / 180, p<.01)$, whereas the deviations from regression were not $(F=1.91, \mathrm{df}=3 / 180$, $p>.05)$. The effects of signal regularity were not significant overall, nor within any of the five levels of signal density ( $\mathrm{F}<1.00$ in each case).

It can be concluded that RT decreased as a linear function of logarithmic increases in signal density over the range from 6 to 96 signals/hr. in both experiments, and that RT was significantly affected by signal regularity at the 6-signals/hr. density in Experiment I, but not in Experiment II.

Performance decrement. In order to test for performance decrements in $\mathrm{RT}^{\prime} \mathrm{s}$ to correct detections, two additional median RT's were computed from the data of each $\mathrm{S}$ in Experiment II. The first was based on S's performance during the period in which he received the first half of the critical signals presented to him, and the second was based on the period during which he received the second half of the critical signals. Thus, these RTs represent, approximately, the performance of $S$ over the first and second halves of the signals; although the actual time involved for any specific $S$ is likely to be different from that of another $\mathrm{S}$, the expected values of the mean times are $1 / 2-\mathrm{hr}$. periods. The mean data, as shown in Fig. 3, may be taken to represent performance during the first and second $1 / 2-\mathrm{hr}$. of the $1-\mathrm{hr}$. watch.

An analysis of variance was computed based on three orthogonal factors (signal densities, signal regularities, and half-signal periods) with a fourth factor (Ss) nested in the first two. The results of this analysis indicated that the effects of signal density and of halfsignal period were statistically significant $(F=8.80$, $\mathrm{df}=4 / 180, \mathrm{p}<.01$, for densities; $\mathrm{F}=6.09$, $\mathrm{df}=1 / 180$, $\mathrm{p}<.01$, for periods). No other effect was significant ( $F<1.00$ in each case).

It is apparent from the data of Fig. 3 and the results of the analysis that RT during the second-half of the watch tended to be longer than during the first half. Although the effect (the decrement in performance) seems from the figure to be greater for the lower signal densities, this effect (the density-by-period interaction) did not approach statistical significance.

Atypical performance. It appeared to $\mathrm{E}$ during the course of data collection that several Ss were atypical in their performances. In order to establish the validity of this observation, and to assess its effects on the analysis and results, those $\mathrm{Ss}$ were identified whose overall median RTs exceeded the mean RT of the subgroup by two standard deviations or more. There were four such Ss in the three subgroups at the signaldensity level of 6 signals $/ h r$., three at 12 signals $/ \mathrm{hr}$., three at 24 , one at 48 , and one at 96 signals $/ \mathrm{hr}$.

The data of these 12 "atypical" Ss were removed from the summary table of Experiment II, as were also the data of an additional $18 \mathrm{Ss}$. The 18 were selected at random in order to reduce the number of Ss in each of the 15 experimental conditions to 11, thereby retaining equal numbers of Ss per cell. Analyses of the

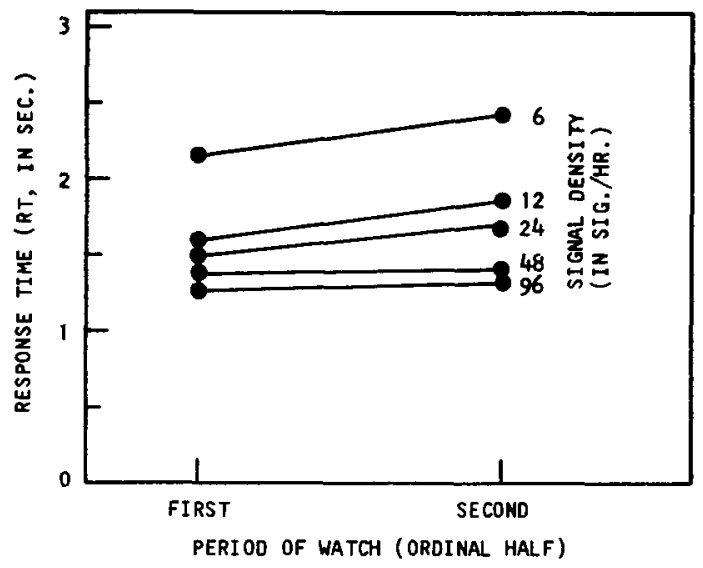

Fig. 3. Response time to correct signal detections as a function of half-signal periods of watch at five levels of signal density. Data of Experiment II. 
remaining data produced results and conclusions identical to those reported for Experiment II in the previous two sections. The data themselves were essentially identical, except for differences in levels of performance.

From this it can be concluded that the effects of temporal uncertainty on watchikeeping performance is not a function of atypical behavior on the part of some Ss, but rather tends to be invariant over Ss.

\section{DISCUSSION}

With respect to overall performance efficiency, as measured by RT to correct signal detections, the data of the present study indicate that there are clear effects due to signal density. The effects of signal regularity, if any, are less clear and will be discussed later.

In general, overall RT decreases as signal density is increased. However, the density or frequency of signals in the watchkeeping task should determine, at least in part, the temporal uncertainty of the signal-the less frequently signals occur, the greater the average uncertainty concerning when they will occur. If the temporal uncertainty due to signal density could be specified, then a test could be made of the applicability of Hick's (1952) law to the watchkeeping situation in addition to the choice-reaction situation for which it was formulated.

That is to say, Hick (1952) has pointed out that the rate of gain of information in choice reactions is a constant, and several other researchers have verified that disjunctive $\mathrm{RT}$ is indeed an increasing linear function of the amount of information transmitted in choice reactions (Crossman, 1953; Gregg, 1954). It is true that other researchers have found conditions under which RT has failed to increase with either uncertainty or the amount of information transmitted (Leonard, 1959; Mowbray \& Rhoades, 1959; Mowbray, 1960), or under which various factors apparently influence the degree of increase (Brainard et al, 1962; Fitts \& Switzer, 1962), but these negative cases appear to have been explained as stimulus-response compatibility effects (Alluisi et al, 1964; Alluisi, 1965). In addition, Klemmer (1956; 1957) has demonstrated that Hick's law holds for temporal uncertainty-i.e., that disjunctive RT is an increasing linear function of the temporal uncertainty of the stimulus in choice-reaction situations. The question now is whether RT to correct signal detections in the watchkeeping task can also be represented as a linear function of the temporal uncertainty of the signal, or what will be called the uncertainty due to signal density.

A metric for specifying the surprisal (Attneave, 1959 , p. 6; Samson, 1951), or specific signal uncertainty, due to signal density has been derived elsewhere (Smith, 1961; Smith \& Alluisi, 1962). The argument runs somewhat as follows: The density-determined temporal uncertainty of a signal event, or the surprisal due to signal density, may be expressed as,

$$
\mathrm{h}(\mathrm{sd})=-\log _{2} \mathrm{P}(\text { signal })
$$

where $h(s d)$ is the information, in bits, associated with the signal's occurrence at a specific time, and where the probability of occurrence of a signal in any of the specified intervals is

$$
P(\text { signal })=D / D(\max )
$$

in which $\mathrm{D}$ is the signal density or actual number of signals per hour, and $D(\max )$ is the maximum number of possible signals per hour (3600 in the present experiments). With signal densities (D's) of 6, 12, 24, 48 , and 96 signals per hour, the associated probabilities $\left(P^{\prime} s\right)$ are $6 / 3600,12 / 3600$, etc., and the surprisals due to signal density ( $h$ 's) are $9.23,8.23,7.23,6.23$, and 5.23 bits, respectively.

The reaction time to correct detections (RT) is shown as a function of the surprisal due to signal density (h) in Fig. 4; the data of both experiments are included in the figure, and the linear function given is the average of the least-squares equations of the lines fitted to the data of the two studies separately. The intercept and slope constants for the data of Experiment I were -0.03 and 0.22 , respectively, and those for the data of Experiment II were 0.16 and 0.20 , respectively. The slope constants (and, therefore, the coefficients of correlation) are significantly greater than zero $(p<.001$ in each case), but they are not significantly different from each other $(z=0.65, p=.52)$. Thus, the functions obtained in the two experiments are essentially identical, and the data may be represented with the single average function shown in Fig. 4.

It is clear from this, and from the results of the analyses of variance and regression analyses reported earlier, that the watchkeeper's RT may be represented as an increasing linear function of temporal uncertainty.

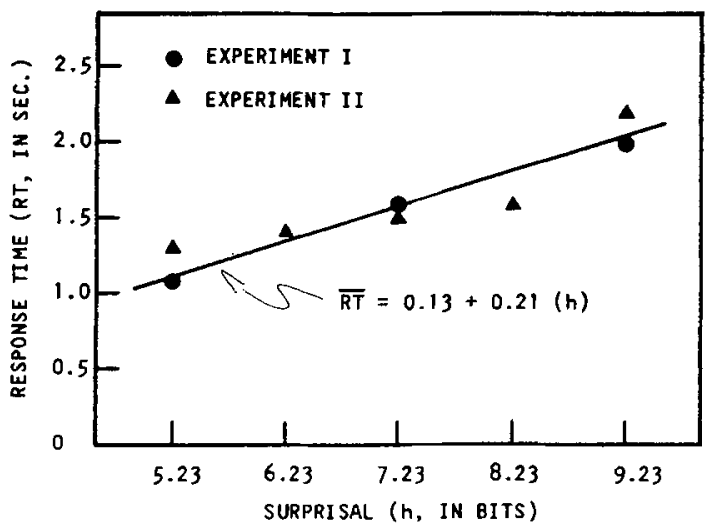

Fig. 4. Response time to correct signal detections as a function of the surprisal (temporal uncertainty) due to signal density. 
That is to say, performance will be a function of the temporal uncertainty of the critical signal in watchkeeping tasks. Thus, psychophysical relations can be demonstrated to hold for watchkeeping tasks, just as they have been demonstrated previously to hold for choice-reaction tasks. Indeed, an interesting line of research might be devoted to measuring the extent to which both tasks can be represented with the same psychophysical functions-i.e., to what extent may the watchkeeping situation be considered a special case of choice reactions!

Now, with regard to signal regularity, the results of Experiment I appear to show an effect, but not those of Experiment II. Yet, because of the greater number of Ss and observations, the tests of statistical significance in Experiment II should have been greater in power than those of Experiment 1, so the difference cannot be assigned to a lack of power. It is tentatively concluded that the positive signal-regularity effect found in Experiment I was a type-I statistical error.

This interpretation is further suggested by the observation, noted in post-experimental interviews, that most Ss in the highest-density lowest-variability condition of each experiment hit upon the device of counting the flashes of the blinking display lights. These Ss obviously acquired a stable temporal expectancy, but this expectancy did not significantly influence their median RTs, so signal regularity per se appeared to have no effect on RT.

Similarly, the decrements in RT over the hour-long watch were affected by neither signal density nor signal regularity. Although performance was poorer during the second half of the watchkeeping period, there was no significant interaction of periods with either signal density or regularity. Other researchers have reported different conclusions; for example, Baker (1959a, b) has found that the decline in performance over time is inversely related to signal regularity, and others have found it inversely related to signal density (Jenkins, 1958; Kappauf \& Powe, 1959). As in the present study, some researchers have found that there is no relation between the decrement function and signal regularity (Boulter \& Adams, 1963; Dardano, 1962; McCormack \& Prysiazniuk, 1961). There is, fortunately, a possible explanation of these diverse results.

In all cases cited above as having found a significant relation between the watchkeeping decrement and either (or both) signal density or regularity, the index of watchkeeping performance employed was the number (or proportion) of missed signals (or its complement, the number of signals correctly detected). In all of the cases cited as having found no significant relation, the index used was the latency or response time (RT) to correct signal detections. This illustrates again (cf., Chinn \& Alluisi. 1964; McGrath, 1963, p. 233) the specificity of the index or measure of watchkeeping performance used; it should serve as a caution that conclusions must be limited to the index employed, and not generalized to all indices of performance efficiency in watchkeeping.

\section{References}

Adams, J. A. Vigilance in the detection of low intensity visual stimuli. J. exp. Psychol., 1956, 52, 204-208.

Adams, J. A. Spatial and temporal uncertainty as determinants of of vigilance behavior. $J$. exp. Psychol., 1964, 67, 127-131.

Alluisi, E. A. Interaction of S-R compatibility and the rate of gain of information. Percept. mot. Skills, 1965, 20, 815-816.

Alluisi, E. A. Attention and vigilance as mechanisms of response. In E. A. Bilodeau (Ed.), Acquisition of skill. New York: AcademPress, 1966. Pp. 201-213.

Alluisi, E. A., Strain, G. S., \& Thurmond, J. B. Stimulus response compatibility and the rate of gain of information. Psychon. Sci., 1964, 1, 111-112.

Attneave, F. Application of information theory to psychology. New York: Holt, Rinehart \& Winston, 1959.

Baker, C. H. Attention to visual displays during a vigilance task: II. Maintaining the level of vigilance. Brit. J. Psychol., 1959a, $50,30-36$.

Baker, C. H. Three minor studies of vígilance. Def. Res. Med. Lab. Rep., Canada, 1959b, No. 234-2.

Baker, C. H. Further toward a theory of vigilance. In D. N. Buckner, \& V. V. McGrath (Eds.), Vigilance: a symposium. New York: McGraw-Hill, 1963. Pp. 127-170.

Bartlett, S. C., Beinert, R. L., \& Graham, J. R. Studies of visual fatigue and efficiency in radar observation. USAF RADC tech. Rep., 1955, No. 55-100.

Boulter, L. R., \& Adams, J.A. Vigilance decrement, the expectancy hypothesis, and intersignal interval. Canad. J. Psychol., 1963, 17, 201-209.

Brainard, R. W., Irby, T. S., Fitts, P. M., \& Alluisi, E. A. Some variables influencing the rate of gain of information. $J$. exp. Psychol., 1962, 63, 105-110.

Broadbent, D. E. Perception and communication. New York: Pergamon, 1958.

Chinn, R. McC., \& Alluisi, E. A. Effect of three kinds of knowledgeof-results information on three measures of vigilance performance. Percept. mot. Skills, 1964, 18, 901-912.

Crossman, E. R. F. W. Entropy and choice time: the effect of frequency unbalance on choice, response. Quart. J. exp. Psychol., 1953, 5, 41-51.

Dardano, I. F. Relationships of intermittent noise, intersignal interval and skin conductance to vigilance behavior. J. appl. Psychol., 1962, 46, 106-114.

Deese, J. Some problems in the theory of vigilance. Psychol. Rev., $1955,62,359-368$.

Deese, J., \& Ormond, E. Studies of detectability during continuous visual search. USAF WADC tech.Rep., 1953, No. 53-8.

Ditchburn, R. W. Some factors affecting efficiency of work of lookouts. Adniralty Res, Lab. Rep., Great Britain, 1943, No. ARL/RI/84.46/0.

Fitts, P. M., \& Switzer, S. Cognitive aspects of information processings: I. the familiarity of S-R sets and subsets. J. exp. Psychol., 1962, 63, 321-329.

Gregg, L. W. The effect of stimulus complexity on discrimination responses. J. exp. Psychol. 1954, 48, 289-297.

Hick, W. E. On the rate of gain of information. Quart. J. exp. Psychol., 1952, 4, 11-26.

Jenkins, H. M. Performance on a visual monitoring task as a function of the rate at which signals occur. M.I.T. Lincoln Lab. tech. Rep., 1953, No. 47.

Jenkins, H. M. The effect of signal rate on performance in visual monitoring. Amer. J. Psychol., 1958, 71, 647-661.

Kappauf, W. E., \& Powe, W. E. Performance decrement at an 
audio-visual checking task. J. exp. Psychol., 1959, 57, 49-56.

Klemmer, E. T. Time uncertainty in simple reaction time. $J$. exp. Psychol., 1956, 51, 179-184.

Klemmer, $\mathbf{E}$. T. Simple reaction time as a function of time uncertainty. J. exp. Psychol., 1957, 54, 195-200.

Leonard, J. A. Factual cholce reactions. Quart. J. exp. Psychol., $1959,11,76-83$.

McCormack, P. D., \& Prysiazniuk, A. W. Reaction-time and regularity of inter-stimulus interval. Percept. not. Skills, 1961, 13, 15-18.

McGrath, J. S. Some problems of definition and criteria in the study of vigilance performance. In D. N. Buckner \& J. J. McGrath (Eds.), Vigilance: a symposium. New York: McGraw-Hill, 1963, Pp. 227-246.

Mackworth, N. H. Researches in the measurement of human performance. Med. Res. Coun., Spec. Rep. Ser., Great Britain, 1950 , No. 268 .

Morgan, B. B., \& Alluisi, E. A. On the inferred independence of of paired watchkeepers. Psychon. Sci., 1965, 2, 161-162.

Mowbray, G. H., \& Rhoades, M. V. On the reduction of choice reaction times with practice, Quart. J. exp. Psychol., 1959, $11,16-23$.

Mowbray, G. H. Choice reaction times for skilled responses. Quart. J. exp. Psychol., 1960, 12, 193-202.

Nicely, P. E., Miller, G. A. Some effects of unequal spatial distribution on the detectability of radar targets. J. exp. Psychol., 1957, 53, 195-198.
Samson, E. W. Fundamental natural concepts of information theory. USAF Cambridge Res. Sta. Rep., 1951, No. E5079.

Smith, R. P. The effects of signal density and signal variability on the efficiency of human vigilance. Unpublished doctoral dissertation, Emory University, 1961.

Smith, R. P., \& Alluisi, E. A. Vigilance performance and the temporal uncertainty of signals. Lockheed-Ga. Co. Human Factors Res. Dept..Rep., 1962.

Warm, J. S., Morris, J. R., \& Kew, J. K. Temporal judgment as a function of nosological classification and experimental methou. J. Psychol., 1963, 55, 287-297.

Woodrow, H. Time perception. In S. S. Stevens (Ed.), Handbook of experimental Psychology. New York: Wiley, 195:. Pp. 1224-1236.

\section{Note}

1. Supported in part by the U. S. Army Medical Research and Development Command, Department of the Army, under Research Contract No. DA-49-193-MD-2567, "Behavioral Effects of Infectious Diseases." Experiment I is based in part on a doctoral dissertati on submitted by the senior author to the Graduate School at Emory University; the dissertation was completed under the direction of the most junior author. Experiment II was conducted principally by the two junior authors at the University of Louisville. All three authors contributed to the analysis and interpretation of the data.

(Received in the Editorial Office July 5, 1966.) 